Int. J. Dev. Biol. 52: 259-265 (2008)

doi: $10.1387 / \mathrm{ijdb} .072338 \mathrm{gp}$

\title{
Germ cell cluster formation and ovariole structure in viviparous and oviparous generations of the aphid Stomaphis quercus
}

\author{
GRAZYNA PYKA-FOSCIAK and TERESA SZKLARZEWICZ* \\ Department of Systematic Zoology, Institute of Zoology, Jagiellonian University, Krakow, Poland
}

\begin{abstract}
The developing ovaries of $S$. quercus contain a limited number of oogonial cells which undergo a series of incomplete mitotic divisions resulting in the formation of clusters of cystocytes. Ovaries of viviparous generations contain 6 to 9 clusters, containing 32 cystocytes each, whereas ovaries of oviparous generations contain 5 clusters containing $45-60$ cystocytes. During further development, clusters become surrounded by a single layer of follicular cells, and within each cluster the cystocytes differentiate into oocytes and trophocytes (nurse cells). Concurrently, cysts transform into ovarioles. The anterior part of the ovariole containing the trophocytes becomes the tropharium, whereas its posterior part containing oocytes transforms into the vitellarium. The vitellaria of viviparous females are composed of one or two oocytes, which develop until previtellogenesis. The nuclei of previtellogenic oocytes enter cycles of mitotic divisions which lead to the formation of the embryo. Ovarioles of oviparous females contain a single oocyte which develops through three stages: previtellogenesis, vitellogenesis and choriogenesis. The ovaries are accompanied by large cells termed bacteriocytes which harbor endosymbiotic microorganisms.
\end{abstract}

KEY WORDS: aphids, Stomaphis quercus, oogenesis, ovariole, cystocyte

\section{Introduction}

Ovarioles of insects are categorized into two types: panoistic and meroistic (for further details see Stys and Bilinski, 1990; Buning, 1994; Bilinski, 1998). Panoistic ovarioles contain oocytes, which form by mitotic divisions (with complete cytokinesis) of oogonial cells. In meroistic ovarioles oogonial cells (termed cystoblasts) undergo divisions with incomplete cytokinesis resulting in the formation of the clusters of interconnected cells termed cystocytes. In each cluster one (in polytrophic ovarioles) or more (in telotrophic ovarioles) cystocyte(s) differentiate(s) into oocyte(s), while the remaining cells become the trophocytes (nurse cells).

In aphids, like in other hemipterans, ovaries consist of telotrophic ovarioles (for description of hemipteran ovaries see Buning, 1994). Each ovariole contains single cluster of germ cells. In advanced families Aphididae and Drepanosiphidae, the initial cystoblast undergoes a series of usually five incomplete mitotic divisions forming cluster of 32 cystocytes (Blackmann, 1978; Buning, 1985). In contrast to advanced aphids, in the primitive family Adelgidae, the cystoblast undergoes five or six successive mitotic cycles followed by the supernumerary divisions of individual cystocytes, which result in the formation of the clusters containing 50-92 cystocytes (Szklarzewicz et al., 2000). In evolutionary advanced families, number of oocytes per cluster is species specific (e.g. in Drepanosiphumplatanoides 16 cystocytes become oocytes, in Metopolophium dirhodum-8), whereas in the evolutionary primitive family Adelgidae this number is not constant and ranges from 14 to 27 (Buning, 1985; Szklarzewicz et al., 2000). The remaining cystocytes differentiate into trophocytes. Since the basic function of these cells is to synthesize RNA-s, their nuclei undergo cycles of endoreplication. Manicardi et al., (1995) showed that the DNA content in the trophocyte nuclei of oviparous generations of an aphid Megoura viciae is equal to 2048C, whereas in viviparous generations to16C.

The ovariole of adult aphids has four well-defined regions: a terminal filament, trophic chamber (tropharium), vitellarium, and ovariole stalk (pedicel) that joins the ovariole with the lateral oviduct (Blackmann, 1978; Buning, 1985; Szklarzewicz et al., 2000). The trophic chamber contains the trophocytes and the early previtellogenic oocytes termed arrested oocytes. The cen-

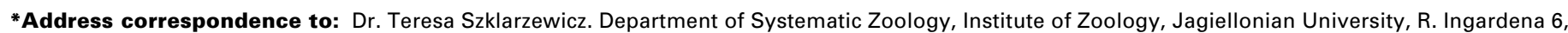
PL-30060 Krakow, Poland. Tel: +4812-663-2437. Fax: +4812-634-3716. e-mail: szkla@iz.uj.edu.pl
}

Published online: 14 February 2008 
tral area of the trophic chamber, termed a trophic core, is free of cells and is filled with the bundles of microtubules. The trophic chamber is surrounded by an inner epithelial sheath of flat somatic cells. In the vitellarium usually two oocytes develop. The vitellarial oocytes are surrounded by a single layer of follicular cells.

Comparative studies on ovaries of five aphid species, representatives of family Aphididae and Drepanosiphidae, showed that besides the difference in the level of the polyploidy of trophocyte nuclei, viviparous and oviparous generations differ in the functioning of the ovaries (Buning, 1985). In viviparous generations the previtellogenic growth of the oocytes is shortened and vitellogenesis as well as choriogenesis are completely blocked.

In the present studies we examined the differences in the development of ovarioles in the generations of an aphid Stomaphis quercus (the life cycle of $\mathcal{S}$. quercus is described in Material and Methods), a representative of the family Lachnidae.

\section{Results}

In all the generations of Stomaphis quercus, when the embryo completes the formation of the blastoderm, the paired ovaries form at the posterior pole of the embryo (Fig. 1A). Each ovary contains several oogonial cells (Fig. 1A). Simultaneously, the embryos are invaded by endosymbiotic microorganisms (Fig. $1 \mathrm{~A})$. Somewhat later, the oogonial cells enter the cycles of mitotic divisions with incomplete cytokineses resulting in a formation of clusters of cells termed cystocytes connected by intercellular bridges (Fig. 1B). The ovaries of viviparous generations form 6 to

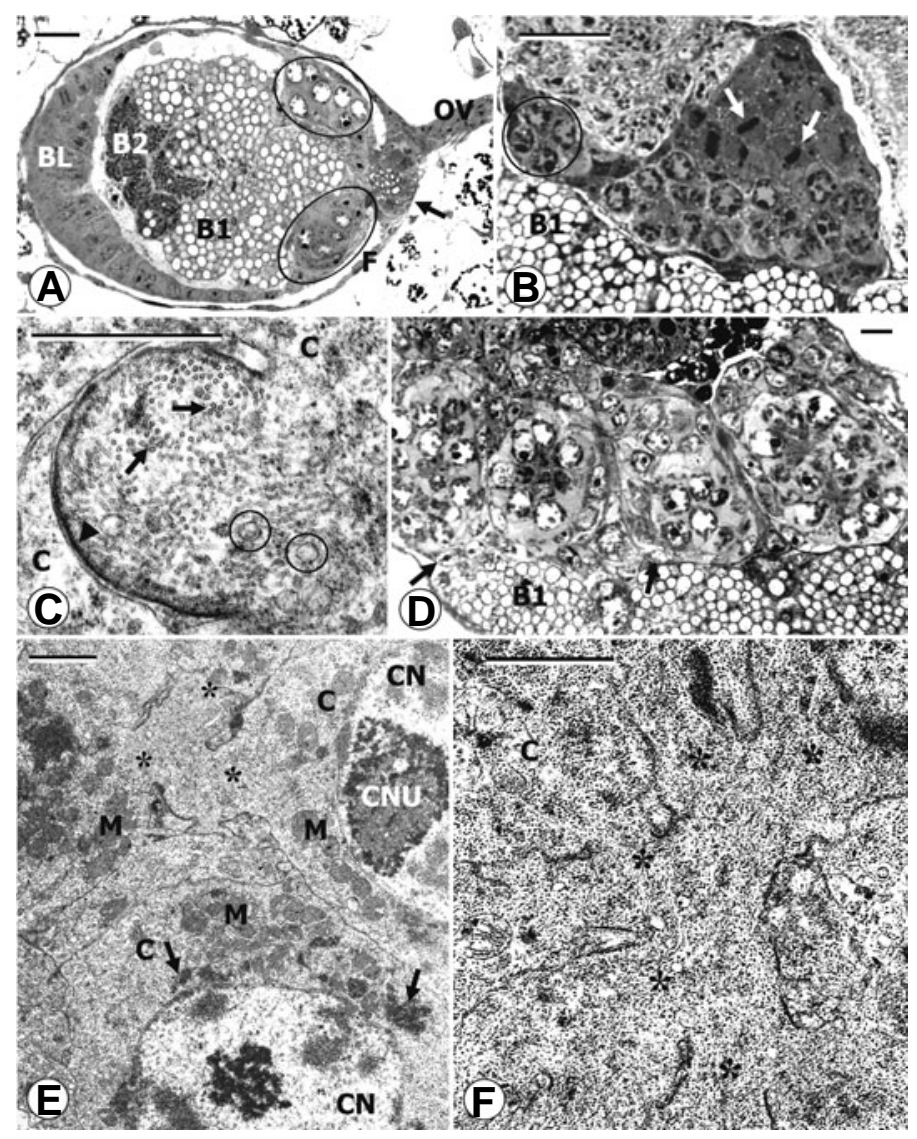

9 clusters, while the oviparous generation - form 5 clusters. The lumen of the intercellular bridges is packed with parallel arranged microtubules and small, smooth vesicles (Fig. 1C). In the next step of cyst development, the cystocytes arrange into a rosette and form a spherical cyst (Fig. 1D). Cysts become covered with a single layer of flat follicular cells (Fig. 1D). Clusters of viviparous generations (fundatrix, V1, V2, sexupara) are composed of 32 cystocytes, and clusters of oviparous generation (sexualis) contain 45 to 60 cystocytes. All cystocytes in the cluster are morphologically similar. They are cone-shaped (Fig. 1D) and their nuclei are large and spherical (Fig. 1D, E). The nuclei in viviparous and in oviparous generations measure about $6 \mu \mathrm{m}$ in diameter. The cystocyte cytoplasm is packed with ribosomes and mitochondria (Fig. 1E). In the perinuclear cytoplasm accumulations of electrondense "nuage" material are present (Fig.1E). Cystocytes open via intercellular bridges into the centre of the rosette (Fig. 1F). In contrast to other hemipterans, the centre of the rosette of Stomaphis quercusdoes not contain the polyfusome (Fig. 1F). During further development, cystocytes differentiate into oocytes and trophocytes (Fig. 2 A, B). Analysis of serial sections of 10 clusters from each generation showed that the clusters of fundatrix, V1, V2 and sexupara generations contain 8 oocytes, whereas the clusters of sexualis generation contain 5 to 8 oocytes. In next step of development the cysts elongate and transform into young ovarioles (Fig. 2C, D). The oocytes occupy the posterior pole of the ovariole, while the trophocytes are localized in its anterior part (Fig. 2C, D). Simultaneously, in the centre of the cluster a trophic core develops (Fig. 2E). During further development, trophocyte nuclei enlarge. In viviparous generations their diameter increases to about $10 \mu \mathrm{m}$, while in oviparous generation to about $30 \mu \mathrm{m}$. The trophocyte nucleoli become prominent (Figs 2C, D, E, 3A, B, C, $4 A)$. Additionally, the trophocyte nuclei of oviparous generation change their shape from spherical (Fig. 2B) to irregular (Fig. 2D). The follicular cells differentiate into two groups: (1) the cells of an inner epithelial sheath and (2) the proper follicular cells (Fig. 2C, D). The inner epithelial sheath envelops the anterior pole of the ovariole containing the trophocytes (Fig. 2C, D). The proper follicular cells surround the posterior pole of the ovariole which contains the oocytes (Fig. 2C, D). During further development, the anterior part of the ovariole transforms into the tropharium and the posterior part into the vitellarium (Fig. 2C).

Fig. 1. Formation of clusters of germ cells. (A) Longitudinal section through the young embryo. The ovaries are filled with oogonial cells (encircled). The posterior pole of the embryo is invaded by endosymbiotic microorganisms (arrow). Methylene blue; bar, $20 \mu \mathrm{m}$. (B) Cross section through the ovary showing the dividing cystocytes (arrows) and clusters of cystocytes forming the rosettes (encircled). Methylene blue; bar, 20 $\mu \mathrm{m}$. (C) Cross section through the intercellular bridge connecting two neighboring cystocytes (C) showing the microtubules (arrows), the ring canal rim (arrowhead) and vesicles (encircled). TEM; bar, $1 \mu \mathrm{m}$. (D) Cysts filled with cystocytes. Follicular cells (arrows) surround each cyst. Methylene blue; bar, $20 \mu \mathrm{m}$. (E) Fragment of the cluster of cystocytes during rosette formation. The intercellular bridges (asterisks), and the accumulations of "nuage" material (arrows) in the perinuclear cytoplasm are visible. TEM; bar, $2 \mu \mathrm{m}$. (F) Central part of the fully grown cyst with the intercellular bridges (asterisks). TEM; bar, $2 \mu \mathrm{m}$. B1, B2, bacteriocytes containing two different types of endosymbiotic bacteria; $B L$, blastoderm; C, cystocyte; CN, cystocyte nucleus; CNU, cystocyte nucleolus; $F$, follicular epithelium; $M$, mitochondria; OV, lateral oviduct. 

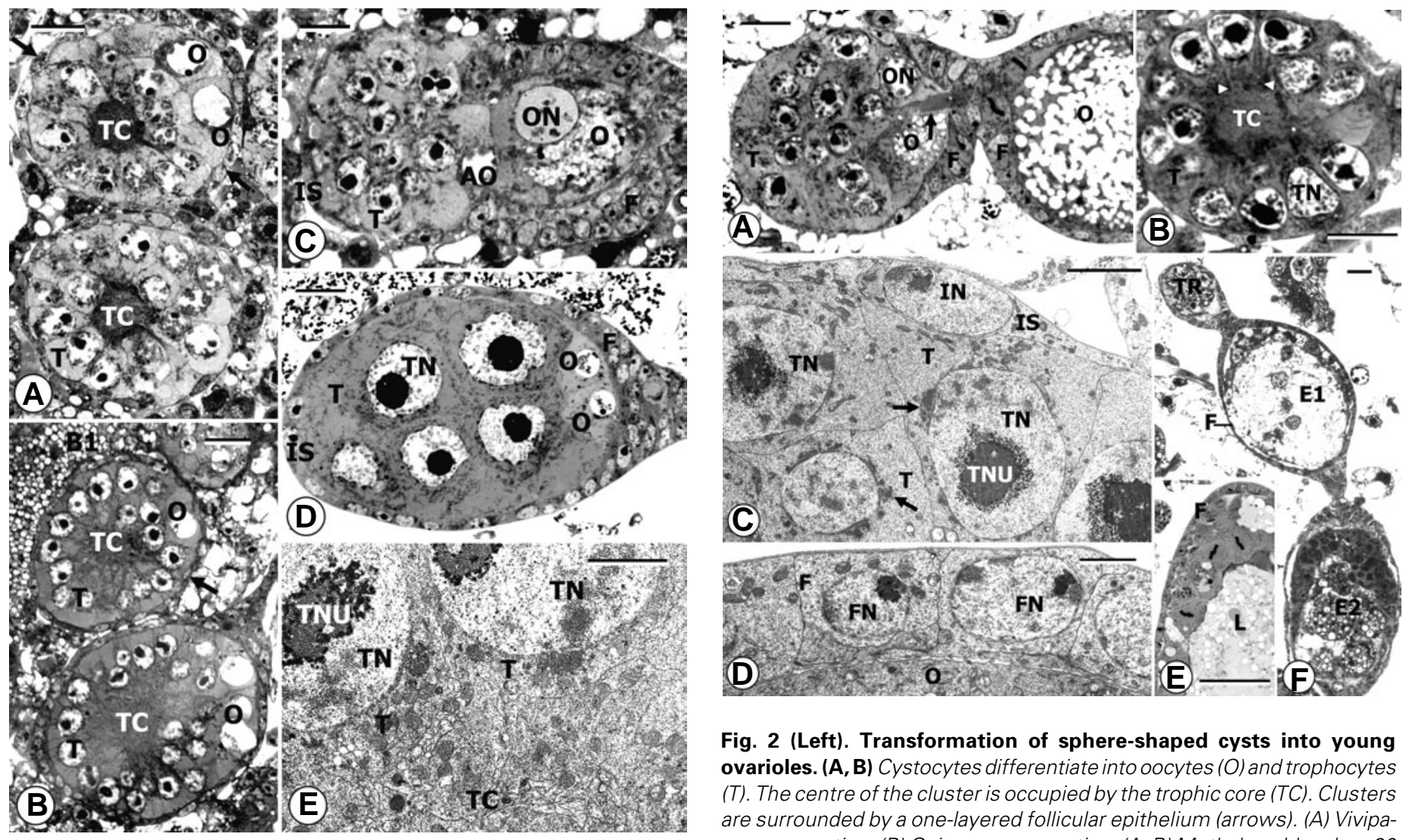

Fig. 2 (Left). Transformation of sphere-shaped cysts into young ovarioles. (A, B) Cystocytes differentiate into oocytes $(O)$ and trophocytes (T). The centre of the cluster is occupied by the trophic core (TC). Clusters are surrounded by a one-layered follicular epithelium (arrows). (A) Viviparous generation, (B) Oviparous generation. (A, B) Methylene blue; bar, 20 $\mu \mathrm{m}$. (C, D) Young ovarioles. Follicular cells are differentiated into the cells of an inner epithelial sheath (IS) which surround the trophocytes (T) and the proper follicular cells which surround the oocytes (O). (C) Viviparous generation, (D) Oviparous generation. (C, D) Methylene blue; bars: (C) 20 $\mu$ m; (D) $50 \mu \mathrm{m}$. (E) Central part of the young ovariole of viviparous generation. Note a characteristic labyrinth of trophocyte membranes. TEM; bar, $2 \mu \mathrm{m}$. $A O$, arrested oocyte; $B 1$, bacteriocytes; $F$, follicular cells; IS, inner epithelial sheath; O, oocyte; ON, oocyte nucleus; $T$, trophocyte; TC, trophic core; TN, trophocyte nucleus; TNU, trophocyte nucleolus.

Fig. 3 (Right). Ovariole of viviparous female. (A, B) Longitudinal section through the ovariole. Nutritive cord (arrow), broad processes of trophocytes (arrowheads). (A, B) Methylene blue; bar, 20 mm. (C) Fragment of tropharium. Arrows indicate accumulations of "nuage" material. TEM; bar, $5 \mu$ m. (D) Fragment of follicular epithelium (F) and oocyte (O) during early previtellogenesis. TEM; bar, $2 \mu m$. (E) Fragment of the embryo. Methylene blue; bar, $20 \mu \mathrm{m}$. (F) Ovariole containing two embryos (E1 and E2). Methylene blue; bar, $50 \mu \mathrm{m}$. F, follicular epithelium; FN follicular celll nucleus; IN, inner epithelial sheath cell nucleus; IS, inner epithelial sheath cell; L, lipid droplets; O, oocyte; ON, oocyte nucleus; T, trophocyte; TC, trophic core; TN, trophocyte nucleus; TNU, trophocyte nucleolus; TR, tropharium.

In oviparous females ovaries are composed of 5 ovarioles. Usually, 1-4 of them degenerate during previtellogenesis. As a rule, in females collected in September the number of degenerating ovarioles is smaller than in females collected at the end of October. In viviparous females number of ovarioles per ovary is not constant and ranges between 6 and 9 . Each ovariole contains long, inconspicuous terminal filament (not shown), trophic chamber (Figs 3A, B, 4A), vitellarium (Fig. 3A) and pedicel (not shown). Terminal filaments of all ovarioles are joined together into a suspensory ligament that anchors the ovary to the fat body (not shown). The tropharium is sphere-shaped with diameter about 65 $\mu \mathrm{m}$ in viviparous females and about $300 \mu \mathrm{m}$ in oviparous females. It is composed of trophocytes and arrested oocytes (Figs 3A, 4A, F). The latter are always located at the base of tropharium (Figs $3 A, 4 A, F)$. The trophic chamber is covered with an inner epithelial sheath, which consists of a single layer of flat somatic cells with slender projections (Fig. $3 \mathrm{C}$ ). The centre of the trophic chamber is occupied by a common cytoplasmic area, termed a trophic core
(Figs 3B, 4A). The trophic core of oviparous females is much larger than in viviparous females. Its diameter measures about 70 $\mu \mathrm{m}$, while in viviparous females $20 \mu \mathrm{m}$. The core is filled with bundles of microtubules (not shown). The trophocytes form processes which extend into the trophic core (Figs 3B, 4A). The trophocyte membranes in the vicinity of the trophic core are folded and intertwined (not shown). Trophocytes possess large nuclei with giant, single nucleoli (Figs 3A, B, C, 4A). Numerous pores perforate the nuclear envelope (Fig. $4 \mathrm{E}$ ). The perinuclear cytoplasm contains accumulations of electron-dense "nuage" material (Figs 3C, 4E). In all the generations "nuage" is accompanied by groups of mitochondria (Figs $3 \mathrm{C}, 4 \mathrm{E}$ ). The remaining cytoplasm is filled with ribosomes and mitochondria (Fig. 3C). In addition, the trophocyte cytoplasm contains numerous rod-shaped endosymbiotic microorganisms (Fig. 4G). Arrested oocytes have large, spherical nuclei with decondensed chromatin (Figs 3A, 4F). In oviparous generation, arrested oocytes have small amount of cytoplasm (Fig. 4F). In viviparous generations arrested oocytes 


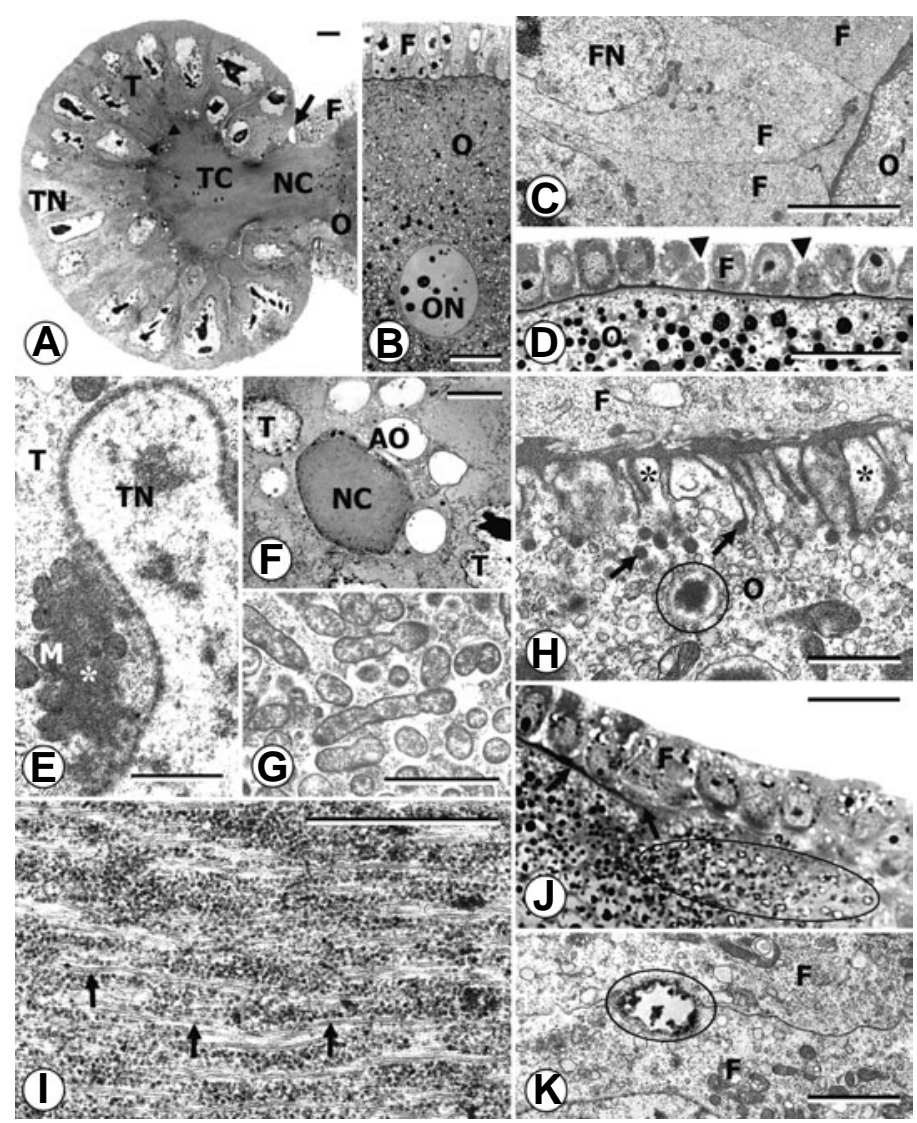

Fig. 4. Ovariole of oviparous female. (A) Longitudinal section through the ovariole. Broad processes of trophocytes (arrowheads), arrested oocyte (arrow). Methylene blue; bar, $20 \mu \mathrm{m}$. (B,C) Fragment of early vitellogenic oocyte (O) and follicular epithelium (F). (B) Methylene blue; bar, $20 \mu \mathrm{m}$. (C) TEM; bar, $2 \mu \mathrm{m}$. (D) Fragment of oocyte (O) and follicular epithelium (F) during mid-vitellogenesis. Note the presence of wide spaces between neighboring cells (arrowheads). Methylene blue; bar, 20 um. (E) Fragment of trophocyte nucleus and perinuclear cytoplasm. Asterisk indicates accumulation of "nuage" material associated with mitochondria (M). TEM; bar, $1 \mu \mathrm{m}$. (F) Cross section through the basal part of tropharium. Methylene blue; bar, $20 \mu \mathrm{m}$. (G) Fragment of trophocyte cytoplasm filled with endosymbiotic microorganisms. TEM; bar, 2 $\mu \mathrm{m}$. (H) Fragment of follicular cell (F) and cortical ooplasm (O). Endocytotic vesicles (arrows), microvilli (asterisks), yolk granule (encircled). TEM; bar, $1 \mu \mathrm{m}$. (I) Fragment of the nutritive cord packed with microtubules (arrows). TEM; bar, $1 \mu \mathrm{m}$. (J) Posterior pole of the oocyte. Incomplete egg envelopes (arrows), endosymbiotic bacteria (encircled). Methylene blue; bar, $20 \mu \mathrm{m}$. (K) Endosymbiotic bacterium (encircled) during migration between neighboring follicular cells. TEM; bar, $2 \mu \mathrm{m}$. $A O$, arrested oocytes; $F$, follicular epithelium; $F N$, follicular cell nucleus; $N C$, nutritive cord; O, oocyte; ON, oocyte nucleus; $T$, trophocyte; TC, trophic core; $T N$, trophocyte nucleus.

are capable of further development, whereas in oviparous females they degenerate. In the vitellaria of viviparous generations two oocytes develop, while in oviparous females only one. The vitellarial oocyte is connected to the core by the broad nutritive cord (Figs 3A, $4 A)$. The nutritive cord is filled by parallel-arranged microtubules and ribosomes (Fig. 4I). The nutritive cords of older ovarioles also contain numerous mitochondria and rod-shaped endosymbiotic bacteria (not shown). In viviparous generations, oocyte surface is usually smooth and the microvilli are rare and short (Fig. 3D). The oocytes of viviparous females do not accumulate yolk and do not become covered with egg envelopes. The only reserve substances which are accumulated in these oocytes, are lipid droplets (Fig. $3 \mathrm{~A})$. Ultrastructure of follicular cells surrounding the oocyte indicates that these cells are not active synthetically (Fig. 3D). Thus, the period of the oocyte growth is very short and stops at the stage of previtellogenesis. Immediately after previtellogenesis, the oocyte nucleus starts to divide to form the embryo (Fig. 3E, F). The embryos are surrounded by closely adhering follicular cells (Fig. $3 E, F)$. When the formation of blastoderm is completed, the follicular cells covering the posterior pole of the embryo separate from each other generating wide opening that enables entry of endosymbiotic microorganisms (Fig. 1A).

Within the body of embryos that develop in fundatrix, V1 and V2 females, the next generations of embryos arise (Fig. 3F). Thus, the body of fundatrix, V1 and V2 females contains two generations of embryos. In contrast, the embryos developing in sexupara females develop into males and females of last generation (sexualis).

In oviparous females, oocyte undergoes three stages of growth: previtellogenesis, vitellogenesis and choriogenesis. The onset of vitellogenesis is manifested by many morphological changes within the oocyte: the oolemma starts to form microvilli and numerous endocytotic vesicles form in the cortical ooplasm (not shown). Later, the first yolk granules are formed (Fig. $4 \mathrm{H}$ ). As vitellogenesis progresses, the size of the ooocyte increases through the accumulation of yolk granules and lipid droplets in its cytoplasm (Fig. 4D, J). Follicular cells surrounding the previtellogenic and early vitellogenic oocytes are cylindrical and closely adhere to each other (Fig. 4A, B, C). The cytoplasm of follicular cells contains ribosomes and mitochondria (Fig. 4C). During mid-vitellogenesis follicular cells separate from each other, generating wide spaces between neighboring cells (Fig. 4D). During advanced vitellogenesis these cells diversify into two subpopulations: the main body cells and cells surrounding the posterior pole of the oocyte. Both subpopulations are morphologically similar, but the main body cells start to produce precursors of egg envelopes much earlier than the latter (Fig. 4J, arrows). Concurrently, the endosymbiotic bacteria invade the posterior pole of the oocyte (Fig. 4J). These microorganisms migrate between neighboring follicular cells (Fig. $4 \mathrm{~K}$ ), enter the perivitelline space, traverse the oolemma and enter the ooplasm (Fig. 4J). When the migration of endosymbionts is completed, the posterior cells start to produce precursors of egg envelopes.

The large cells termed the bacteriocytes accompany the ovaries of viviparous and oviparous females (Figs. 1 A,B,D, 2B). In Stomaphis there are two types of bacteriocytes: bacteriocytes containing large, spherical bacteria belonging to the genus Buchnera aphidicola (Figs 1A, B, D, 2B, 3F) and bacteriocytes housing smaller, coccoid bacteria (Fig. 1A). Apart from endosymbionts that are harbored in the cytoplasm of the bacteriocytes, the rod-shaped, small bacteria are also present in the cytoplasm of the germ cells (i.e. cystocytes, trophocytes and oocytes) (Fig. 4G).

\section{Discussion}

\section{Morphology of the ovaries}

Present and previous studies have shown that the general organization of ovaries is similar in different families of aphids 
(Blackmann, 1978; Buning, 1985, Szklarzewicz etal., 2000). There are, however, differences in ovary structure in advanced versus primitive families as well as in viviparous females versus oviparous females. In advanced families such as Aphididae and Drepanosiphidae (Buning, 1985), the ovarioles contain 32 germ cells, whereas in the primitive family Adelgidae (Szklarzewicz et al., 2000) number of germ cells is much larger and varies from 50 to 92 . These indicate that during the phylogeny of aphids, like in phylogeny of scale insects, the reduction of the number of germ cells per cluster took place (Szklarzewicz et al., 2000). Buning (1985) studied ovaries of five aphid species belonging to families Aphididae and Drepanosiphidae and found that in viviparous generations there is a shortening of the previtellogenic growth of the oocyte, vitellogenesis and choriogenesis are absent, and the trophocyte nuclei have a lower level of ploidy than those in oviparous generation. Our studies showed that ovaries of viviparous and oviparous females of Stomaphis quercus, a member of family Lachnidae, differ in the number of ovarioles, number of germ cells per ovariole and course of oogenesis. In oviparous females ovaries contain 5 ovarioles, whereas in viviparous females the number of ovarioles is larger and variable. Since Leather et al., (1988) made similar observations for the representatives of five families of aphids, it is possible that the variability in ovariole numbers is typical for the viviparous generations.

In viviparous females all ovarioles develop, while in oviparous females some of them degenerate. Moreover, because the number of degenerating ovarioles is much larger in late autumn than in early autumn females, the late autumn females lay less eggs. It seems probable that the number of degenerating ovarioles (and laid eggs) is regulated by the availability of nutrients (i.e. quality of phloem sap). This hypothesis corresponds well with the observations of Wiktelius and Chiverton (1985) that the bird cherry-oat aphids, Rhopalosiphum padi feeding on low-quality hosts have lower number of ovarioles.

Analysis of serial sections showed that the ovarioles of oviparous females of Stomaphis quercus contain more trophocytes than those of viviparous generations. In addition, the trophocytes of oviparous females are much larger than those in viviparous females. This fact indicates that the level of ploidy of trophocytes is much higher in oviparous than in viviparous females. Manicardi etal., (1995) have demonstrated, using cytofluorometric analysis, that in an aphid Megoura viciae, the enlargement of trophocyte nuclei is related to the overreplication of the whole genome. These authors have experimentally proved that the initiation of endoreplication is correlated with the formation of ommatidia in the embryo. This finding strongly supports an earlier hypothesis that the degree of DNA overreplication in trophocyte nuclei of aphids is influenced by photoperiod (Lees, 1973). In addition, the transition from viviparous generations to oviparous generation correlates with the shortening of day length (Lees, 1960; Dixon, 1971).

In viviparous and in oviparous females of Stomaphis quercus, the trophocytes exhibit all characteristics typical for the trophocytes: large nuclei containing massive nucleoli, accumulation of "nuage" material in the close neighborhood of nuclei and enormous number of ribosomes in the cytoplasm. Such an ultrastructure is related to the basic function of trophocytes, i.e. synthesis of RNA$s$ and subsequent transport of ribosomes, mitochondria and endosymbiotic microorganisms via nutritive cords to the develop- ing oocytes. Like in other hemipterans, nutritive cords of Stomaphis are tightly packed with microtubules that are responsible for the transport of macromolecules as well as organelles from trophic chamber into developing oocytes (Stebbings, 1988).

The main differences in the functioning of ovaries between viviparous and oviparous females concern the length and mode of oocyte growth. In oviparous females, oocytes accumulate yolk (during vitellogenesis) and become covered with egg envelopes (during choriogenesis), whereas in viviparous females oocytes stop developing at the end of previtellogenesis. In viviparous and in oviparous females oocytes are surrounded by a single layer of follicular cells. However, ultrastructural observations showed that follicular cells are synthetically active in the oviparous generation only. In this generation, follicular cells diversify into two subpopulations - the main body cells and posterior cells. The former start to synthesize precursors of egg envelopes much earlier than the posterior cells which results in the temporary lack of egg envelopes in the region of the posterior pole of the oocyte. The incomplete egg coverings enable the entry of endosymbiotic bacteria from the body cavity into the ovaries (see below). Such phenomenon is very rare within insects and has been described previously only in the scale insect Palaeococcus fuscipennis (Szklarzewicz et al., 2006).

The existence of the "embryo in embryo" is of special interest. Moran (1992) called this strategy of development as "a consequent telescoping of generations". According to this author, a beginning of development before the mother is born results in the shortening of postnatal developmental period and leads to higher rate of reproduction.

\section{Development of clusters of germ cells}

Our observations showed that in viviparous as well as in oviparous generations of Stomaphis quercus, development of clusters of germ cells occurs through the similar pathway, and the main differences lie in the number of germ cells present in the clusters. In contrast to representatives of family Aphididae and Drepanosiphidae (Buning, 1985) in which all the generations have the same number (32) of cystocytes, the clusters of oviparous females of Stomaphis are composed of larger number of cystocytes (i.e. 45-60) than those in viviparous females (i.e. 32). Moreover, clusters in oviparous females do not obey Giardina's rule, which states that the cystocyte number $(N)$ is given by the formula: $N=2^{n}$, where " $n$ " defines the number of cystoblast divisions. Since we never observed symptoms of degeneration of cystocytes, we postulate that their irregular number is the consequence of asynchrony of their divisions. Thus, the initial cystoblast undergoes a series of five divisions and some of the cystocytes enter the sixth division. Similar situation has been described in polytrophic ovaries of neuropterans (Kubrakiewicz, 1997) and beetles (Jaglarz, 1998) and in telotrophic ovaries of scale insects (Szklarzewicz and Bilinski, 1995; Szklarzewicz, 1997, 1998a, b) and primitive aphids (Szklarzewicz et al., 2000).

Our detailed studies of development of clusters clearly show that each cyst transforms into single ovariole. Thus, the individual ovariole contains single cluster of interconnected germ cells. Buning (1985) suggested that in aphids, each ovariole-anlage contains several germ cells. Then, only one of them starts to divide, whereas the remaining cells degenerate. However, our analysis of serial sections has shown that in Stomaphis, the 
number of oogonial cells is limited and these cells do not exhibit any symptoms of degeneration, which suggests that each oogonial cell develops into the cluster.

The results of present study and Buning's (1985) observations of developing ovaries in Aphididae and Drepanosiphidae, indicate that the most characteristic feature of developing clusters is a lack of recognizable fusomal material inside the intercellular bridges and consequently lack of a polyfusome extending through the ring canals into all cystocytes. It is generally accepted that the polyfusome is responsible for the coordination of cystocyte divisions, i.e. their synchronization, restriction of their number, arrest of cystocyte cytokinesis and the differentiation of germ cells (see Storto and King, 1989; de Cuevas et al.,1997 for further details). The presence of polyfusomes has been observed in scale insects (sister group of aphids) (Szklarzewicz, 1997, 1998a, b) as well as in remaining hemipterans (Buning, 1994). According to Buning (1985), the role of polyfusome in aphid clusters may be substituted by persisting microtubules. Our observations (see Fig. 1C) strongly support this hypothesis. Buning (1998) suggested also that the aphids might contain fusome but it is underdeveloped or shortlived which makes it hard to visualize. For the same reasons also the presence of polyfusome may be overlooked. Similar situation has been described in two other closely related groups, in snakeflies and alderflies. Jedrzejowska and Kubrakiewicz (2004) detected polyfusome in developing clusters of the snakefly Raphidia, whereas the alderfly Sialis lacks the polyfusome (Buning, 1979). Jedrzejowska and Kubrakiewicz (2004) postulated that the polyfusome in alderflies might be easily overlooked due to the short period of its occurrence.

We observed that the lumen of intercellular bridges of $S$. quercus contains numerous, small, and ribosome deficient vesicles. Similar structures have been found inside the bridges connecting cystocytes in Drosophila melanogaster (Koch and King, 1966; Mahowald, 1971). Until recently, the nature and origin of these vesicles were unknown, but Snapp and coworkers (2004) using live cell imaging techniques found them to be elements of the continuous endoplasmic reticulum which extends through all the cystocytes constituting the cluster. According to these authors, common endoplasmic reticulum may be responsible for the synchronization of mitotic divisions.

\section{Transovarial transmission of endosymbiotic bacteria}

The ovaries of Stomaphis, like of most aphids, are accompanied by large cells termed bacteriocytes. The cytoplasm of these cells is tightly packed with endosymbiotic bacteria. It is generally known that presence of endosymbionts (bacteria or yeasts) in the insect body is related to their restricted diet, i.e. diet deficient in some essential substances (see Douglas, 1989, 1998; Bauman, 2005, for further details). Since aphids feed on phloem poor in essential amino acids, their endosymbionts are responsible for the amino acid synthesis and their delivery to the host insect (Douglas and Prosser, 1992). Numerous studies have shown the most aphids contain the endosymbiotic bacterium Buchnera aphidicola (Baumann et al., 1995; Douglas, 1998; Sabater et al., 2001; Baumann, 2005). Besides Buchnera, aphids usually harbor additional endosymbionts (called secondary endosymbionts) (Buchner, 1965; Sabater et al., 2001; Baumann, 2005). The bacterium Buchnera, like primary endosymbionts of other insects, is essential for growth and reproduction of the host insect, whereas the role of secondary endosymbionts is still under discussion (Baumann, 2005). Primary endosymbionts are transmitted from one generation to the next transovarially (vertically), i.e. through the female gametes. In contrast, secondary endosymbionts may be inherited vertically and/or horizontally. Our studies have shown that in the body of Stomaphis quercus harbors Buchnera and two types of secondary endosymbionts. In Stomaphis, both Buchnera and secondary endosymbionts are transmitted transovarially. Although endosymbioses (i.e. types of microorganisms, their distribution, function and evolution) in aphids have been extensively studied, the mode of endosymbiont transmission is poorly known. Buchner (1965) described the process of egg infection in several aphid species. Miura et al. (2003) and Braendle et al. (2003) observed the origin of bacteriocytes in Acyrthosiphon pisum, a member of family Aphididae. However, there is no ultrastructural data concerning this process. In vivipaparous generations of Stomaphis quercus bacteria invade embryos, whereas in oviparous generation oocytes are infested. In all the generations, the beginning of the invasion is correlated with the development of the germ cells. Embryos formed in viviparous generations are invaded at the time the germ cells start to form ovaries. In oviparous generation bacteria invade choriogenic oocytes. Thus, our observations support earlier hypothesis that the migration of endosymbionts into ovaries is induced by an unknown factor released from the ovaries (Eberle and Mc Lean, 1982; Zelazowska and Bilinski, 1999; Szklarzewicz and Moskal, 2001; Szklarzewicz et al., 2006).

\section{Materials and Methods}

\section{Insects}

A Stomaphis quercus life cycle consists of five yearly generations (Lorenz and Scheurer,1998). The first four generations (i.e. fundatrix, V1, V2, sexupara) are viviparous and reproduce parthenogenetically. The last, bisexual generation (i.e. sexualis) appears in the autumn. Sexualis females are oviparous. These females lay fertilized eggs that overwinter. In the spring these eggs hatch into larvae that develop into the first viviparous generation (i.e. fundatrix).

Adult females of Stomaphis quercus (L.) were collected from stems of Betula verrucosaand Quercus sessilis in Beskid Sadecki Mountains and Ojcow National Park (south Poland). The females of viviparous generations have been collected from May to September. The females of oviparous generation have been collected in September and October.

\section{Light and electron microscopy}

Dissected embryos and ovaries were fixed in $2.5 \%$ glutaraldehyde in $0.1 \mathrm{M}$ phosphate buffer $(\mathrm{pH} 7.4)$ at room temperature. After being washed in phosphate buffer, the material was postfixed in $1 \%$ osmium tetroxide in $0.1 \mathrm{M}$ phosphate buffer $(\mathrm{pH} 7.4)$, dehydrated in a series of alcohol and acetone, and embedded in epoxy resin Epox 812 (Fullam Inc., Latham, N.Y., USA). Semithin sections were stained with $1 \%$ methylene blue in $1 \%$ borax and photographed in a Jenalumar (Zeiss Jena) microscope. Ultrathin sections were stained with lead citrate and uranyl acetate and examined using a JEM 100 SX electron microscope at $80 \mathrm{kV}$.

\section{Acknowledgements}

We would like to express our gratitude to Professor Szczepan Bilinski for suggesting this species for examination and providing first 
specimens. We also thank to M.Sc. Wladyslawa Jankowska and Dr. Beata Szymanska for their skilled technical assistance. This work was supported by funds from the research grant from Ministry of Science and Informatization: 2 PO4C 00427.

\section{References}

BAUMANN, P. (2005). Biology of bacteriocyte-associated endosymbionts of plant sup sucking insects. Annu. Rev. Microbiol. 59: 155-189.

BAUMANN, P., BAUMANN, L., LAI, C.Y., ROUHBAKHSH, D., MORAN, N.A. and CLARK, M.A. (1995). Genetics, physiology, and evolutionary relationships of the genus Buchnera: intracellular symbionts of aphids. Annu. Rev. Microbiol. 49: $55-94$.

BILINSKI, S. M. (1998). Introductory remarks. Folia Histochem. Cytobiol. 3: $143-$ 145.

BLACKMANN, R.L. (1978). Early development of the parthenogenetic egg in three species of aphids (Homoptera: Aphididae). Int. J. Insect Morphol. Embryol. 7: 33-44.

BRAENDLE, C., MIURA, T., BICKEL, R., SHINGLETON, A.W., KAMBHAMPATI, S. and STERN, D.L. (2003). Developmental origin and evolution of bacteriocytes in the aphid - Buchnera symbiosis. PLOS Biol. 1: 71-76.

BUCHNER, P. (1965). Endosymbiosis of animals with plant microorganisms. Interscience, New York.

BUNING, J. (1979). The telotrophic - meroistic ovary of Megaloptera. I. The ontogenetic development. J. Morphol. 162: 37 - 44.

BUNING, J. (1985). Morphology, ultrastructure and germ cell cluster formation in ovarioles of aphids. J. Morphol. 86: $209-221$.

BUNING, J. (1994). The ovary of Ectognatha, the insects s.str. In The Insect Ovary: Ultrastructure, Previtellogenic Growth and Evolution (ed. Buning J.). Chapman and Hall, London, pp. 31-305.

BUNING, J. 1998. The ovariole: structure, type and phylogeny. In Microscopic Anatomy of Invertebrates, vol. 11C. Insecta (ed. Harrison, W.F. and Locke, M.). Wiley-Liss, New York, pp. 897-932.

DE CUEVAS, M., LILLY, M.A. and SPRADLING, A.C. (1997). Germline cyst formation in Drosophila. Annu. Rev. Genet. 31: 405-428.

DIXON, A.F.G. (1971). The "interval timer" and photoperiod in the determination of parthenogenetic and sexual morphs in the aphid, Drepanosiphum platanoides. J. Insect. Physiol. 17: 251-260.

DOUGLAS, A.E. 1989 Mycetocyte symbiosis in insects. Biol. Rev. 64: 409-434.

DOUGLAS, A.E. (1998). Nutritional interactions in insect - microbial symbioses: aphids and their symbiotic bacteria Buchnera. Annu. Rev. Entomol. 43: 17-37.

DOUGLAS, A.E. and PROSSER, W.A. (1992). Synthesis of an essential amino acid tryptophan in the pea aphid (Acyrthosiphon pisum) symbiosis. J. Insect Physiol. 38: $565-568$.

EBERLE, M.W. and MC LEAN, D.L. (1982). Initiation and orientation of the symbiote migration in the human body louse Pediculus humanus L. J. Insect Physiol. 28: $417-422$.

JAGLARZ, M.K. (1998). The number that counts. Phylogenetic implications of the number of nurse cells in ovarian follicles of Coleoptera-Adepghaga. Folia Histochem. Cytobiol. 36: 167-178.

JEDRZEJOWSKA, I. and KUBRAKIEWICZ, J. (2004). Ovariole development in telotrophic ovaries of snake flies (Raphidioptera). Folia Biol. Krakow 52: 175184.

$\mathrm{KOCH}$, E.A. and KING, R. (1966). The origin and early differentiation of the egg chamber of Drosophila melanogaster. J. Morphol. 119: 283-304.

KUBRAKIEWICZ, J. (1997). Germ cells cluster organization in polytrophic ovaries of Neuroptera. Tiss. Cel/29: 221-228.

LEATHER, L.R., WELLINGS, P.W. and WALTERS, K.F.A. (1988). Variation in ovariole number within the Aphidoidea. J. Nat. History 22: 381-393.

LEES, A.D. (1960). The role of photoperiod and temperature in the determination of parthenogenetic and sexual forms in the aphid Megoura viciae Buckton - II. The operation of the "interval timer" in young clones. J. Insect Physiol. 4: 154175.

LEES, A.D. (1973). Photoperiodic time measurement in the aphid Megoura viciae (Buckt.). J. Insect Physiol. 19: 2279-2316.

LORENZ, H. and SCHEURER, S. (1998). Biology and generation - order of Stomaphis quercus (Lachnidae) living on Betula pendulanear Berlin, Germany. In Aphids in natural and managed ecosystems (ed. Nafria, N.J.M. and Dixon, A.F.G). Universidae de Leon, Leon, pp. $243-250$.

MAHOWALD, A.P. (1971). The formation of ring canals by cell furrows in Drosophila. Z.Zellforsch. 118: 162-167.

MANICARDI, G.C., GALLI, A., MALAVASI, A. and BONVICINI PAGLIAI, A.M. (1995). DNA content in the nurse cell nuclei of viviparous and oviparous females of Megoura viciae (Homoptera, Aphididae). Invert. Reprod. Dev. 28: 1 - 6.

MIURA, T., BRAENDLE, C., SHINGLETON, A., SISK, G., KAMBHAMPATI, S. and STERN, D.L. (2003). A comparison of parthenogenetic and sexual embryogenesis of the pea aphid Acyrthosiphon pisum (Hemiptera: Aphidoidea). J. Exp. Zool. 295B: 59-81.

MORAN, N.A. (1992). The evolution of aphid life cycle. Annu. Rev. Entomol. 37 : 321-348.

SABATER, B., VAN HAM, R.C.H.J., MARTINEZ-TORRES, D, SILVA, F. LATORRE,A.and MOYA, A. (2001). Molecular evolution of aphids and their primary (Buchnerasp.) and secondary endosymbionts: implications for the role of symbiosis in insect evolution. Interciencia 26: 508-512.

SNAPP, E.L., LIDA, T., FRESCAS, D., LIPPINCOTT-SCHAWARTZ, J. and LILLY, M.A. (2004). The fusome mediates intercellular endoplasmic reticulum connectivity in Drosophila ovarian cysts. Mol. Biol. Cel/ 15: 4512-4521.

STEBBINGS, H. (1988). Translocation along microtubules in insect ovarioles. J. Cytol. Subcell. Biol. 10: 1 - 14.

STORTO, P.D. and KING R.C. (1989). The role of polyfusomes in generating branched chains of cystocytes during Drosophilaoogenesis. Dev. Genet. 10:70 $-86$.

STYS, P. and BILINSKI, S.M. (1990). Ovariole types and the phylogeny of hexapods. Biol. Rev. 65: 401-429.

SZKLARZEWICZ, T. (1997). Structure and development of the telotrophic ovariole in ensign scale insects (Hemiptera, Coccomorpha: Ortheziidae). Tiss. Cel/29: $31-38$.

SZKLARZEWICZ, T. (1998a). Structure of ovaries of scale insects. I. Pseudococcidae, Kermesidae, Eriococcidae and Cryptococcidae (Insecta, Hemiptera, Coccinea). Int. J. Insect Morphol. Embryol. 27: 167 - 172.

SZKLARZEWICZ, T. (1998b). Structure of ovaries of scale insects. II. Margarodidae (Insecta, Hemiptera, Coccinea). Int. J. Insect Morphol. Embryol. 27: 319-324.

SZKLARZEWICZ, T. and BILINSKI, S.M. (1995). Structure of ovaries in ensign scale insects, the most primitive representatives of Coccomorpha (Insecta, Hemiptera). J.Morphol. 224: 23-29.

SZKLARZEWICZ, T., WNEK, A., and BILINSKI, S.M. (2000). Structure of ovarioles in Adelges laricis, a representative of the primitive aphid family Adelgidae. Acta Zool. (Stockholm) 81: 307 - 313.

SZKLARZEWICZ, T. and MOSKAL, A. 2001. Ultrastructure, distribution, and transmission of endosymbionts in the whitefly Aleurochiton aceris Modeer (Insecta, Hemiptera, Aleyrodinea). Protoplasma 218: 45 - 53.

SZKLARZEWICZ, A., KEDRA, K. and NIZNIK, S. (2006) Ultrastructure and transovarial transmission of endosymbiotic microorganisms in Palaeococcus fuscipennis (Burmeister) (Insecta, Hemiptera, Coccinea: Monophlebidae). Folia Biol. Krakow 54: 69-74.

WIKTELIUS, S, and CHIVERTON, P.A. (1985). Ovariole number and fecundity for the two emigrating generations of the bird cherry-oat aphid (Rhopalosiphum padi) in Sweden. Ecol. Entomol. 10: 349-355.

ZELAZOWSKA, M. and BILINSKI, S.M. (1999). Distribution and transmission of endosymbiotic microorganisms in the oocytes of the pig louse, Haematopinus suis (L.) (Insecta: Phthiraptera). Protoplasma 209: 207-213. 


\section{Related, previously published Int. J. Dev. Biol. articles}

See our recent Special Issue Developmental Biology in Poland edited by Kloc, Maleszewski and Tarkowski at: http://www.ijdb.ehu.es/web/contents. php?vol=52\&issue=2-3

See our Special Issue Mammalian Reproduction \& Development in honor of Anne McLaren and edited by Brigid Hogan at: http://www.ijdb.ehu.es/web/contents.php?vol=45\&issue=3

Accumulation and dynamics of proteins of the MCM family during mouse oogenesis and the first embryonic cell cycle

Lukasz Swiech, Katarzyna Kisiel, Renata Czolowska, Maciej Zientarski and Ewa Borsuk

Int. J. Dev. Biol. (2007) 51: 283-295

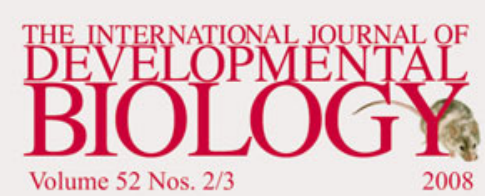

Characterization of novel genes expressed specifically in the sexual organs of the planarian Dugesia ryukyuensis

Sumitaka Hase, Emiko Kashiwagi, Kazuya Kobayashi, Motonori Hoshi and Midori Matsumoto

Int. J. Dev. Biol. (2007) 51: 345-349

Stage-specific regulation of programmed cell death during oogenesis of the medfly Ceratitis capitata (Diptera, Tephritidae) Athanassios D. Velentzas, loannis P. Nezis, Dimitrios J. Stravopodis, Issidora S. Papassideri and Lukas $\mathrm{H}$. Margaritis

Int. J. Dev. Biol. (2007) 51: 57-66

Germ-plasm specification and germline development in the parthenogenetic pea aphid Acyrthosiphon pisum: Vasa and Nanos as markers

Chun-che Chang, Wen-chih Lee, Charles E. Cook, Gee-way Lin and Tschining Chang

Int. J. Dev. Biol. (2006) 50: 413-421

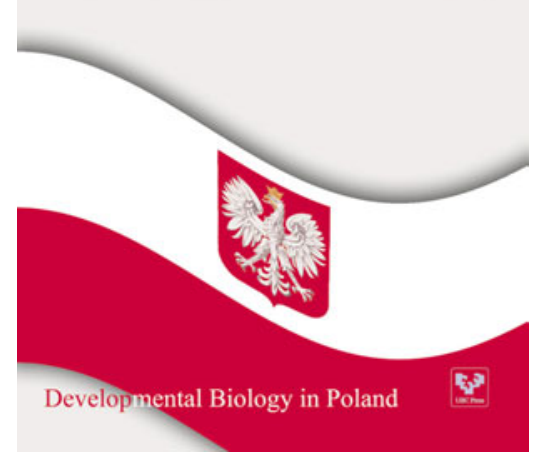

2006 ISI ${ }^{\star \star}$ Impact Factor $=3.577^{\star *}$

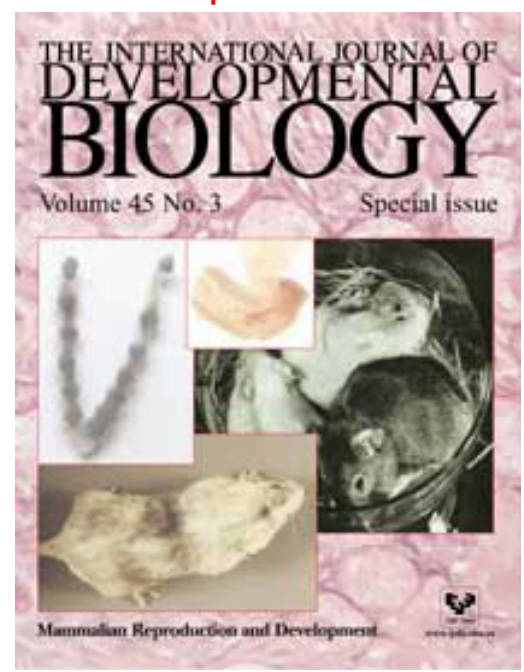

